\title{
Secondary School Transition and the Use of Different Sources of Information for the Construction of the Academic Self-concept
}

\author{
Burkhard Gniewosz, University of Würzburg, Jacquelynne S. Eccles, \\ University of Michigan, and Peter Noack, Friedrich-Schiller-University \\ Jena
}

\begin{abstract}
This study focuses on processes involved in students' academic self-concept constructions before, during, and after secondary school transition. The study is based on a four-wave longitudinal dataset $(N=1953)$. Structural equation modeling showed that during school transition, the impact of grades on students' academic self-concepts in Math and English decreased whereas the effects of maternal competence perceptions increased. After the transition, the effects of grades increased, while the effects maternal competence beliefs decreased again. The results are interpreted in terms of differential emphasizing of sources of information for students' self-concept construction. During school transition, elementary school grades lost informational value for selfevaluations due to the changed frame of reference. To secure stable and valid selfassessments, students emphasized other sources than grades; in this, case information obtained through parental competence appraisals. After transition, when valid grades were available for the students' constructions again, the temporarily heightened parental influence decreased again.
\end{abstract}

Keywords: academic competence beliefs; grades; parents; school transition

\section{Introduction}

The current study focuses on the development of the academic self-concept. Especially in the time of secondary school transition, there are numerous individual and environmental changes for adolescents. We investigated the association of this particular school transition with the differential importance of informational sources for the self-concept construction, namely grades and parental competence beliefs about their children, for the students' construction of their academic self-concepts.

Correspondence should be addressed to Burkhard Gniewosz, Department of Educational Research, University of Würzburg, Campus Hubland-Nord, Oswald-Külpe-Weg, Haus 86, D-97074 Würzburg. Email: burkhard.gniewosz@uni-wuerzburg.de 


\section{Academic Self-concept}

Over the last decades, a tremendous amount of research focused on adolescents' self-concept has been conducted by scholars from various fields. This work has demonstrated three important things: (1) the importance of academic ability-related self-concepts for behavior, (2) the importance of both academic performance information and parental beliefs as influences on the ontogeny of academic self-concepts; and (3) the decline over time in academic self-concepts of children and adolescents (Eccles \& Wigfield, 2002; Marsh, 1990; Marsh, Köller, Trautwein, Lüdtke, \& Baumert, 2005; Skaalvik \& Rankin, 1995). We built upon these findings in this article.

When they begin elementary school, children lack experiences in achievementrelated situations and the resulting differential feedback. Students begin school with unrealistically high expectations and ability beliefs (Eccles, Midgley, \& Adler, 1984; Nicholls, 1979) and become more accurate in their self-evaluations and expectations with growing experience in achievement-related situations (Eccles, Wigfield, Harold, \& Blumenfeld, 1993; Spinath \& Spinath, 2005). Thus, in the course of development, the self-concept of ability is assumed to become increasingly accurate and stable at the inter-individual level (Harter, 1998; Marsh, 1990). However, work originating from social psychological theorizing has shown that self-evaluations, such as self-concepts of ability, themselves as well as the processes of self-evaluation are flexible and driven by individual motives, such as self-verification (individuals' striving for highly certain self-knowledge), self-enhancement (individuals' striving for favorable selfknowledge), or self-assessment (individuals' striving for accurate self-knowledge) (Elliot \& Mapes, 2005; Festinger, 1954, 1957; Sedikides, 1993). These motives for stable, accurate, and positive self-images lead to a selective processing of available information in the construction of self-beliefs. Self-concept, therefore, is seen as an adaptive construct at the individual level.

\section{Sources of the Academic Self-concept}

The construction of one's ability self-concepts is influenced by a variety of sources of information (Eccles [Parsons], 1983; Skaalvik \& Skaalvik, 2002); one major source being ability-related feedback (e.g., Eccles [Parsons], 1983; Marsh et al., 2005). Grades serve as competence indicators in several ways. They constitute an external frame of reference within an academic domain and an internal frame of reference between different academic domains (Marsh, 1986; Skaalvik \& Skaalvik). The external, between-student frame of reference describes social comparisons with other students on the same dimension, for example, 'In math I am better than most of the other students'. The internal, within-student frame of reference is defined as dimensional comparisons, for example, 'I am better in math than in English'.

Above and beyond academic performance, the reflected appraisal of others plays an important role in the construction of achievement related self-views (Eccles [Parsons], 1983). There is a large body of research showing that the ability beliefs by significant others, such as peers (Cole, Maxwell, \& Martin, 1997) and teachers (Bouchey \& Harter, 2005; Cole et al., 1997; Spinath \& Spinath, 2005) affect students' selfperceptions. By the same line of argument, the role of parents as interpreters of reality has been demonstrated convincingly (Bouchey \& Harter; Cole et al.; Dai, 2002; Frome \& Eccles, 1998; Gniewosz, 2010; Jacobs \& Eccles, 1992; Spinath \& Spinath). Thus, students construct their ability beliefs based on both achievement-related feedback 
(grades) and the appraisals of their parents. Parents can communicate their perception of their offspring's achievement in a variety of ways: for example, parents may provide different learning opportunities based on their views of their children's ability or they may directly tell their children which skills the children are best at. According to the Eccles et al. model of parental influences on motivational beliefs, children interpret these cues and incorporate them into the self-concept of ability (Jacobs, Davis-Kean, Bleeker, Eccles, \& Malanchuk, 2005; Jacobs \& Eccles, 2000).

Over the last years, research in this field has been enriched by widening the focus from investigating processes within one single academic domain toward a more holistic view. Achievement-related choices are best understood by considering alternatives and other choices together (Eccles \& Wigfield, 2002). A prominent model addressing this line of thought is the internal/external frame of reference model (Marsh, 1986; Skaalvik \& Skaalvik, 2002). Research has provided evidence that students use achievement-related feedback in terms of grades (e.g., Marsh \& Hau, 2004; Skaalvik \& Rankin, 1995) and parental competence perceptions (Gniewosz, 2010), from more than one domain in their own competence assessments in a given academic domain. Thus, when depicting processes involved in adolescents' self-concept constructions, it is important to consider sources of information from more than one academic domain. We chose the domains of Math and English because both can serve as proxies for the major domains of the academic self-concept: mathematical and verbal.

\section{School Transitions}

A time of major changes in the development of academic beliefs and values is during school transitions (Eccles et al., 1993). Meckelmann (2004) regards the school transition as a critical life event. Watt (2004) described this time period as most critical for the development of academic ability self-concepts. Although there are individual patterns of changes after school transitions (Berndt \& Mekos, 1995; Eccles et al., 1989; Harter, Whitesell, \& Kowalski, 1992; McDougall \& Hymel, 1998), there are some general developments. A decline in the self-concept of ability ratings or competence beliefs in almost all subjects at school is well documented during elementary and secondary school (e.g., Cole et al., 2001; Eccles et al., 1984; Meckelmann; Spinath \& Spinath, 2005; Wigfield, Eccles, Mac Iver, Reuman, \& Midgley, 1991). These changes have been shown to be maximal during the time of school transitions (Eccles et al., 1984; Watt, 2004).

An explanation of the decline of the self-concept is provided by stage environment fit theory (Eccles, 2004; Eccles et al., 1993). The transition to secondary school marks a change in school environment. After the transition, students are placed in new classrooms that can be regarded as new frames of reference. They have to cope with new peers (targets of social comparisons) and teachers (sources of comparison information). Moreover, a lot of structural changes take place. Students are confronted with a stronger emphasis on teacher authority (Harter et al., 1992; Midgley, Feldlaufer, \& Eccles, 1988, 1989), ability grouping (Eccles \& Midgley, 1989), less autonomy (Harter et al., 1992; Seidman, Allen, Aber, \& Mitchell, 1994), more social comparisons implied by feedback structures (Harter et al., 1992; Rosenholtz \& Simpson, 1984), and stricter grading practices (Eccles \& Midgley, 1989; Finger \& Silverman, 1996), than in elementary school. These changes, together with the disruption of earlier social networks (Wigfield, Byrnes, \& Eccles, 2006), do not fit the developmental changes starting around puberty, namely the intensified need for autonomy, peer orientation, 
and identity formation (cf. Eccles, Wigfield, \& Schiefele, 1998; Wigfield \& Wagner, 2005). This poor fit of individual (stage) and contextual (environment) changes is argued to lead to the declining ability beliefs during school transition.

Above and beyond the mean changes, competence-related self-assessments have been shown to be less stable during secondary school transition than the time before and after the transition (Cole et al., 2001; Eccles et al., 1989; Hoge, Smit, \& Hanson, 1990). In a large $(\mathrm{N}=1920)$ two-cohort longitudinal study, Cole et al., 2001) depicted changes in the six-month stabilities of various domains of the self-concept through grades three to 11 . During the secondary school transition, the authors were able to show sharp decreases in the stabilities of the academic and social self-concept. Thus, academic self-views are destabilized during this transition time.

Students are used to assessing their ability level based on grades (see Marsh et al., 2005). But due to changes in grading practices and changes in the frames of reference after the transition (Eccles \& Midgley, 1989; Finger \& Silverman, 1996), grades originating from the time before the transition may lose their predictive power for the construction of competence-related beliefs following the transition. Since there is the basic need for competence-related self-evaluation (Deci \& Moller, 2005; Festinger, 1954; James, 1892), and a motive for consistent and stable (self-verification motive) as well as accurate self-assessments (Elliot \& Mapes, 2005; Festinger, 1957; Sedikides, 1993), the individual can be expected to fill this information gap by active information seeking (Pomerantz, Saxon, \& Kenney, 2001; Ruble, 1994; Ruble \& Seidman, 1996). The decreased amount of information derived from elementary school grades for the academic self-concept constructions during school transition might lead to increased exploration because of the individual's need for stable and accurate self-views (see self-verification and self-assessment motives). Therefore, other sources of information than grades may become more important for the construction of the academic self-concept during such transitional times in order to fill the information gap. Given the prominent role of parents as social sources of information, an increase in parental influence on students' competence-related beliefs can be expected.

\section{The Present Study}

This study, based on a longitudinal dataset, Michigan Study of Adolescent and Adult Life Transitions (MSALT, Eccles et al., 1989), directly focuses on the association of the secondary school transition period and changes in students' constructions of their self-concepts of ability in the domains of Math and English.

Firstly, we expect that the effect of school grades on students' competence-related beliefs will decline during school transition when the most recent grades that can be used for the construction of the students' ability beliefs are those obtained in elementary school, that is, in a different external frame of reference. Because of the change in the frame of reference, the pre-transition grades are expected to have a lower predictive power for the self-assessments in the new frames of reference- the secondary school, as compared to elementary school.

Secondly, because there is the need for an accurate self-evaluation and because grades are assumed to be less predictive, other sources in ability-related information are hypothesized to show an increase in their importance for the self-concept construction in order to compensate for the information gap caused by the lack of valid grade information. Research has shown that the parental perceptions of the student's 
competencies are important sources for the student's ability belief constructions (e.g., Fredricks \& Eccles, 2002; Frome \& Eccles, 1998; Spinath \& Spinath, 2005). We expect parental competence perceptions to be less affected by school transition and more stable than the students' ability beliefs because parents base their competence appraisals of their children on observations over a longer time period as compared to the grade time frame of one term or one school year. Moreover, parents have the opportunity to observe their offspring dealing with ability-related tasks in situations outside the school setting, for example, reading, solving Sudoku puzzles. Thus, parental perceptions of their offspring's academic abilities based on these observations together with the information obtained from the school-based achievement feedback can be expected to be less susceptible to changes in the school context. Therefore, information obtained through parental perceptions is expected to provide a valid source of information for the students' own construction during the time of school transition. Accordingly, we expect the effect of the parental competence perceptions to be increased during the time of school transition.

Thirdly, after the transition, when valid grades are obtained in the new context, we expect the influence of the grades on the students' academic self-concept to increase again. Hence, the temporarily increased effects of the parental perceptions are expected to decrease again when valid grade information is available again.

\section{Method}

\section{Sample}

The sample is a wave-one-to-four subsample from MSALT (Eccles et al., 1989), including maternal data. Participants completed questionnaires twice a year over this two-year period. Wave one and two were conducted in fall and spring term (1983) when students attended sixth grade, prior to the school transition. Data of wave three and four were collected in fall and spring term of the seventh grade (1984). The junior high school transition took place between waves two and three. Twelve school districts located in low- to middle-income communities participated. The districts are located within a 50-mile radius of a large city in the Midwestern USA. Almost 90 percent of the students in these districts are of European-American descent; families served by these schools are predominantly middle class. All the teachers who taught Mathematics to sixth-grade students scheduled to make a transition the next year to junior high were recruited for the first two waves of data collection; 95 percent of the teachers (117 classrooms from 55 schools) agreed to participate. All of these teachers' students were asked to participate in the study, and 79 percent agreed and received parental permission. All of the year 2 (third and fourth wave of data collection) Math teachers agreed to participate in the study. There was an attrition rate of 14 percent in the students' sample, almost entirely due to students' families moving out of the sampled school districts. For this study, the data of the students attending sixth grade at $\mathrm{T} 1$ was used $(\mathrm{N}=1953)$. Approximately 1850 students completed questionnaires at all four waves. Participants' gender was approximately equally distributed (male T1: 47.3 percent; T2: 48.0 percent; T3: 47.3 percent; T4: 47.8 percent). The mean ages in the student sample are T1: $10.9(S D=0.63)$; T2: $11.3(S D=0.72)$; T3: $12.0(S D=0.59)$; T4: $12.4(S D=0.67)$. The parental dataset contains self-reports from 1672 mothers at T1; 1263 mothers at T2; 1240 mothers at T3, and 1220 mothers at T4. 


\section{Measures}

The MSALT study was designed to tap a wide range of students' motivational constructs and competence-related beliefs (see Eccles et al., 1989). Students' ratings regarding their ability beliefs were measured by four items in each academic domain: e.g., 'How good at math are you?' (Response format: 1- 'not at all good' to 7- 'very good'), 'If you were to rank all the students in your math class from the worst to the best in math, where would you put yourself'? (Response format: 1- 'the worst' to 7'the best'), 'In general, how hard is math for you'? (Response format: 1-'very easy' to 7- 'very hard'), and 'Compared to most other school subjects you have taken or are taking, how hard is math for you'? (Response format: 1- 'my easiest' to 7- 'my hardest course'). The wording for English as academic subject was the same. The Cronbach's alphas were: Math T1: .76, T2: .81, T3: .78, T4: .81; English T1: .73, T2: .78, T3: .79, T4: 81 .

The maternal assessments of student's competence in Math and English were measured by three items, each: 'In general, I believe that my child is . . ' (response format: 1- 'not at all good at math' to 7- 'very good at math'), 'My child finds math ...' (Response format: 1- 'very easy' to 7- 'very hard'), and 'How well is your child doing in math this year'? (Response format: 1- 'not at all well' to 7-'very well'). The wording for English as academic subject was the same. The Cronbach's alphas were: Math T1: .83, T2: .79, T3: .83, T4: .83; English T1: .83, T2: .80, T3: .85, T4: .83.

The following Math and English grades were obtained from the students' school records: sixth grade fall term, sixthth grade spring term, and seventh grade fall term. Because grading practices varied somewhat across the school districts, all grades were converted to the same numerical system that ranged from $01=F$ to $16=A+$. All districts used the standard $A$ to $F$ grading format at grade 7 . Although most of the elementary schools also used this format for grade 6, a few used either numeric scores (1-100) or a U, NI, S, O format that included $+\mathrm{s}$ and $-\mathrm{s}$. These formats were converted to the $0-16$ format with $U=1, N I=6 ; S-=9 ; S=12 ; S+=15 ; O=16$. This conversion created distributions as equal to the $A$ to $F$ distributions in the other school districts.

\section{Analyses}

The hypotheses were tested in a longitudinal structural equation model. This model was based on data from four waves of the MSALT dataset. The data of the first two waves were collected prior to the school transition and wave three and four after the transition. Thus, we have the opportunity to model longitudinal paths between grades, maternal competence perceptions, and students' self-concepts of ability before, during, and after the transition, controlled for stabilities of the dependent variables. The tested model is depicted in Figure 1.

The primary dependent variables were the students' self-concept of abilities in the academic domains Math and English. For each time point, both self-concepts (Math and English) were predicted by Math and English grades, received the preceding term, and both maternal competence perceptions (same measurement occasion as the students' ratings, cf. Cohen, Cohen, West, \& Aiken, 2003). Maternal beliefs were regressed on the preceding Math and English grades as well. Furthermore, the withindomain autoregressive paths from the preceding measurement occasions were modeled for students' and parents' ability beliefs as well as for the grades to control for construct stabilities. ${ }^{1}$ In the case of the students' self-concepts of abilities, the 
cross-domain auto-regressions (e.g., self-concept Math T1 $\rightarrow$ self-concept English T2) were estimated as well (not depicted in Figure 1). Paths from self-concept of ability on the grades within domain were added (same measurement occasion).

For each self-concept of ability, two item parcels, including two items each, were created to serve as manifest indicators for one latent variable. The latent variables depicting maternal competence perceptions were estimated based on three manifest variables (items). Within the error covariance matrix (TE-matrix), the diagonal and the covariances between the error terms of those manifest variables, referring to parallel formulated items/the same item parcels between domains and measurement occasions, were set free to control for measurement variance (see correlated uniqueness; Marsh, Byrne, \& Craven, 1992).

Within the variance/covariance-matrix of the latent variables/residuals (PSI-matrix), the covariances between all students' competence beliefs, all covariances between grades, all covariances between maternal competence perceptions, as well as all within T1 covariances were set free. This is a very strict model, because all other covariances are restricted to be zero. This holds, for instance, for all covariations of grades, student's ability beliefs, and maternal perceptions of the student's competence between measurement occasions if not modeled as directed effects (see above). We decided on this model to secure clear interpretability of the results and a parsimonious parameterization of the model.

There were missing values in the dataset. In a first step, the missing values were tested whether they were completely at random (Little, 1988; Schafer \& Graham, 2002). Only the missing values for the Math self-concepts were not completely at random $(M C A R), \chi^{2}(20, \mathrm{~N}=1953)=43,37, p<.01$. For English self-concept as well as Math and English parental competence perceptions, the missing values proved to be completely missing at random, $\chi^{2}(26, \mathrm{~N}=1953)<36.6, p>.05$. In case of missing completely at random (MCAR), cases with missing data could have been deleted

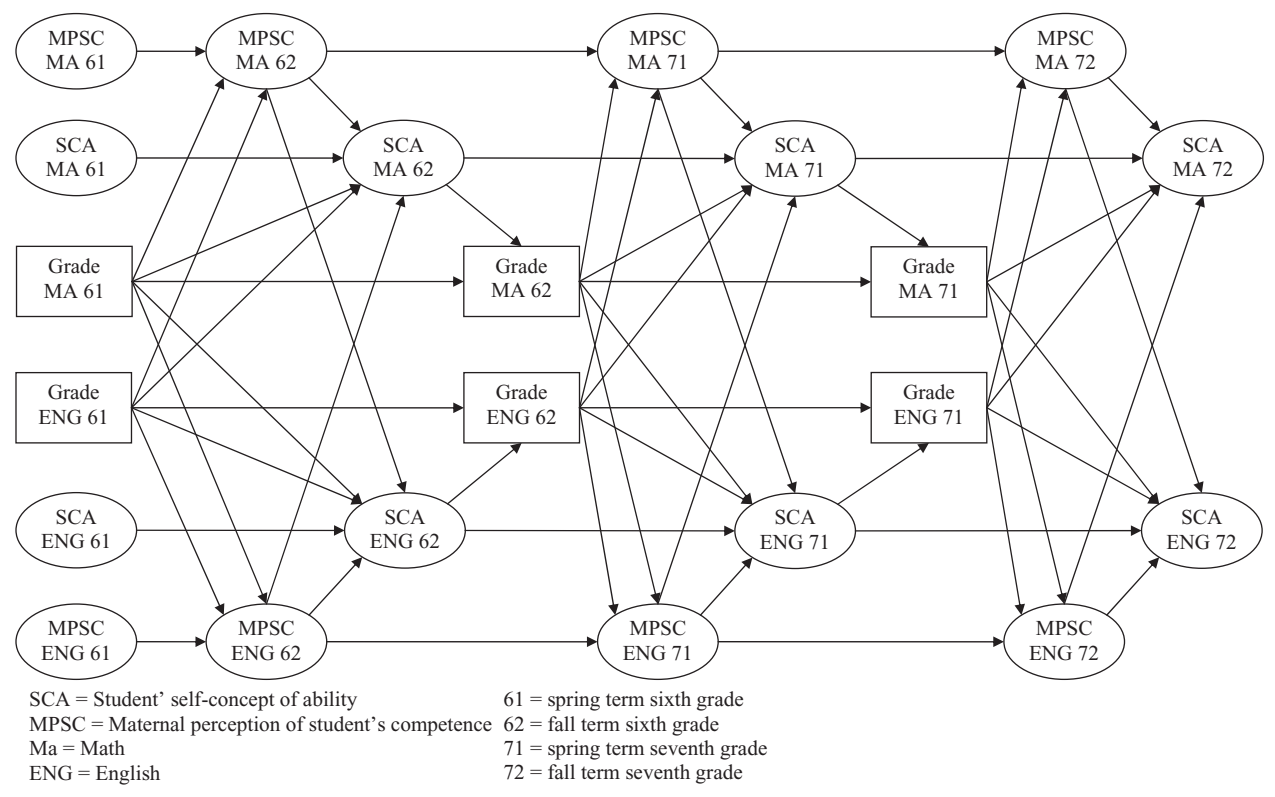

Figure 1. Longitudinal Conceptual Structural Equation Model. 
without biased parameter estimations. In order to avoid losing statistical power and the missing values in math self-concepts not being MCAR, we chose a model-based approach of dealing with missing data. Using the software used Mplus 4.2 (Muthén \& Muthén, 2006), the $M L R$ estimator was employed. Thus, cases with missing data were not excluded, but all model parameters were estimated, based on the cases with complete data and the (conditional) missing values under the missing at random assumption (Arbuckle, 1996). A correlation table of all variables in the structural equation models and the missing values in the relevant constructs is presented in the appendix (Table A1). The low number of missing values could be predicted by the grades. Thus, low achieving students were more likely to have missing values.

Moreover, the data were collected within classroom, resulting in a nested data structure. Due to the violation of the independence of observation assumption for standard SEM, ignoring the data structure would lead to biased estimations of the standard errors (Raudenbush \& Bryk, 2002). Therefore, the MLR estimator implemented in the Mplus software was applied to correct the estimations.

In a last step, between-time point differences in the hypothesized effects were tested. For this purpose, the regression weights were restricted to be equal between waves. If the model fit of the restricted model is significantly worse than in the non-restricted model, the between-wave differences in the regression weights are significant. Since the obtained fit statistics by the FIML/MLR in Mplus are based on a scaled $\chi^{2}$, differences in the model fits cannot be determined by conventional difference $\chi^{2}$-tests because the difference between two scaled chi-squares for nested models is not distributed as chi-square. Thus, an alternative procedure for scales chi-squares as suggested by Satorra and Bentler (1999) was applied.

\section{Results}

\section{Descriptive Results}

Means and standard deviations of the dependent variables are presented in Table 1. In a repeated measures multivariate analyses of variance, the means of those variables (academic self-concepts and parental competence perceptions) were tested on differences between measurement occasions as well as between academic domains. The measurement occasions (T1-T4) as well as the academic domain (Math, English) were

Table 1. Means and Standard Deviations

\begin{tabular}{|c|c|c|c|c|c|c|c|c|}
\hline & \multicolumn{2}{|c|}{$\mathrm{T} 1$} & \multicolumn{2}{|c|}{$\mathrm{T} 2$} & \multicolumn{2}{|c|}{$\mathrm{T} 3$} & \multicolumn{2}{|c|}{$\mathrm{T} 4$} \\
\hline & $M$ & $S D$ & $M$ & $S D$ & $M$ & $S D$ & $M$ & $S D$ \\
\hline \multicolumn{9}{|c|}{ Self-concept of ability } \\
\hline Math & 4.92 & 1.14 & 4.94 & 1.13 & 4.87 & 1.10 & 4.80 & 1.18 \\
\hline English & 4.76 & 1.12 & 4.82 & 1.15 & 4.67 & 1.18 & 4.67 & 1.21 \\
\hline \multicolumn{9}{|c|}{$\begin{array}{l}\text { Parental competence } \\
\text { beliefs }\end{array}$} \\
\hline Math & 5.14 & 1.21 & 5.16 & 1.14 & 5.11 & 1.26 & 5.02 & 1.31 \\
\hline English & 5.00 & 1.28 & 5.05 & 1.13 & 4.87 & 1.32 & 4.86 & 1.27 \\
\hline
\end{tabular}


specified as within-subject factors. Results indicate a decline in all dependent measures over time: academic self-concepts, $F(3,1770)=7.49, p<.01, \eta^{2}=.01$; parental competence perceptions: $F(3,1770)=13,82, p<.01, \eta^{2}=.02$. Moreover, mothers, as well as the students themselves, indicated a higher perceived competence in Math than in English: academic self-concepts, $F(1590)=14.28, p<.01, \eta^{2}=.02$; parental competence perceptions: $F(1,590)=16.03, p<.01, \eta^{2}=.02$. There were no significant interactions. Difference contrasts between measurement occasions indicated significant changes in students self-concepts between all four measurement occasions, $F_{\mathrm{s}}(1$, $590)>4.2$, s $<.05$. For mothers, only the changes from T2 to T3, $F(1,590)=16.51$, $p<.01$, and T3 to T4, $F(1,590)=20.64, p<.01$, were significant. Taken together, mean change patterns were quite comparable between students and mothers, during and after school transition.

\section{SEM Results}

The strict longitudinal model, as described above (see Figure 1), showed an acceptable model fit, $\chi^{2}(810, \mathrm{~N}=1953)=2841.74, p<.01$; $\mathrm{RMSEA}=.03, \mathrm{SMR}=.06$; $\mathrm{CLI}=.96$; $\mathrm{TLI}=.94$. Although the $\chi^{2} /$ d.f. ratio is bigger than the proposed ratio of $3: 1$ (Kline, 1998), the fit indices together with strict assumptions formulated in the model suggest acceptance of the proposed model.

The results of the structural equation model are summarized in Table 2. A full correlation table, including stabilities, of the used constructs can be taken from Table A2 in the Appendix. The autoregressive paths of students' and maternal competence beliefs can be taken from Table A3 in the Appendix.

The pre-transition stabilities (see Table A2) of the students' academic self-concepts were higher (Math: $r=.77$; English: $r=.62$ ) than the stabilities during transition (Math: $r=.63$; English: $r=.48$ ). The post-transition stabilities increased again for English self-concept (Math: $r=.64$; English: $r=.63$ ). As predicted, the maternal competence perceptions were more stable during the school transition (Table A2; Math: pre-transition: $r=.82$, during transition: $r=.74$, post-transition $r=.78$; English pre-transition: $r=.81$ during transition: $r=.75$ post-transition: $r=.81$ ).

Within the Math domain, pre-transition grade significantly predicted changes in the academic self-concept (spring term sixth grade: $\beta=.12^{* *}$ ). During school transition, this effect was not significant (fall term seventh grade: $\beta=.06$ ). After school transition, Math grades again predicted changes in the ability beliefs (spring term seventh grade: $\beta=.25^{* *}$ ). In English domain, the pattern of grade effects was comparable, although both coefficients were not statistically significant (spring term sixth grade: $\beta=.08$; fall term seventh grade: $\beta=.00$; spring term seventh grade: $\beta=.22^{* *}$ ). There were no significant cross-domain grade effects on academic self-concepts in either domain.

Within-domain grades significantly predicted the changes in maternal competence perceptions (Math: spring term sixth grade: $\beta=.21^{* *}$; fall term seventh grade: $\beta=.12^{*}$; spring term seventh grade: $\beta=.36^{* *}$; English: spring term sixth grade: $\beta=.27^{* *}$; fall term seventh grade: $\beta=.14^{*}$; spring term seventh grade: $\beta=.34^{* *}$ ). No cross-domain effects were found.

Maternal competence perceptions significantly predicted the changes in students' self-concepts of abilities within both domains (Math: spring term sixth grade: $\beta=.28^{* *}$; fall term seventh grade: $\beta=.48^{* *}$; spring term seventh grade: $\beta=.38^{* *}$; English: spring term sixth grade: $\beta=.26^{* *}$; fall term seventh grade: $\beta=.46^{* *}$; spring term seventh grade: $\left.\beta=.16^{* *}\right)$. Between academic domains maternal perceptions 


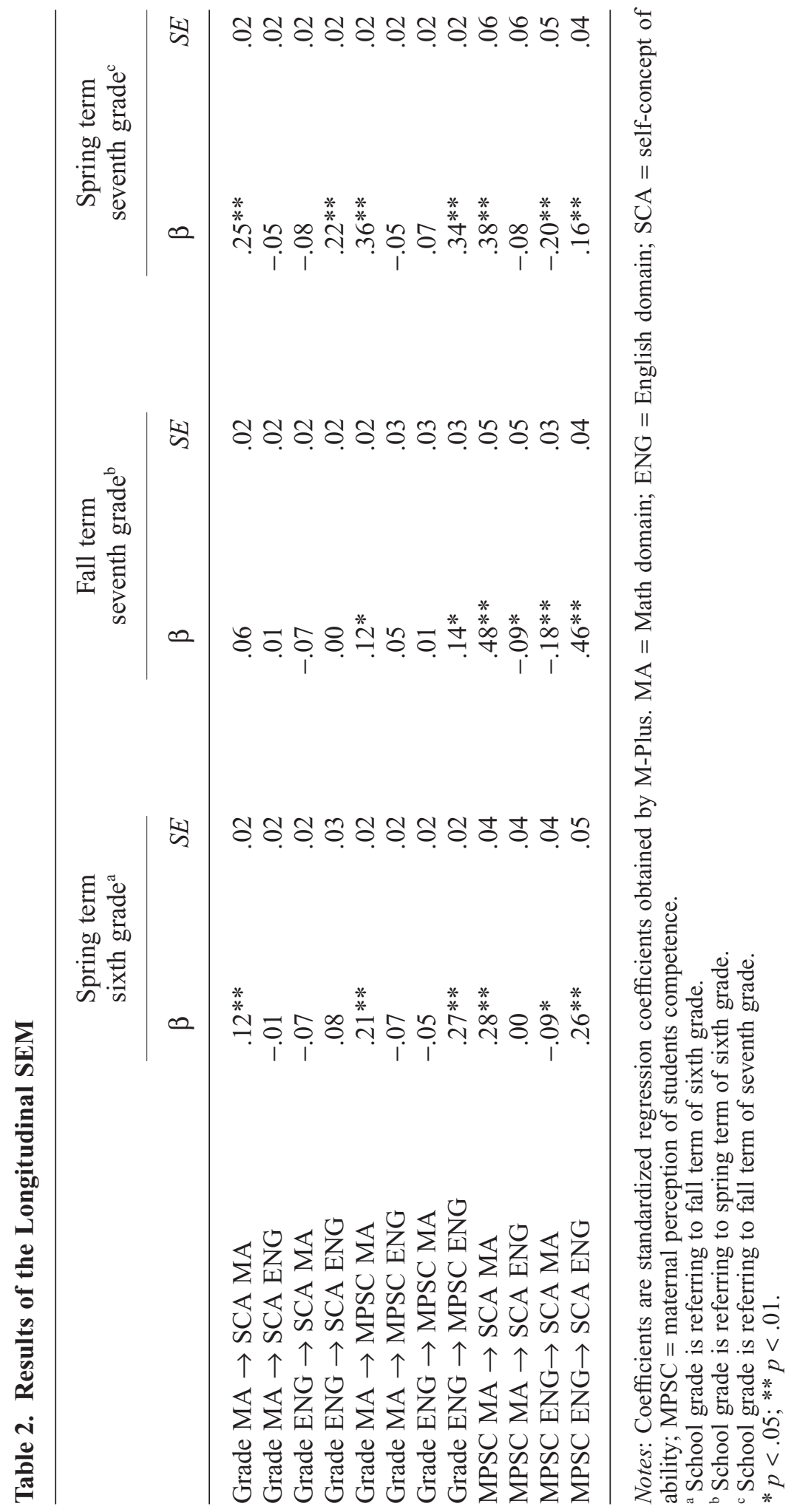


regarding the students' English competence negatively predicted students' Math competence beliefs (spring term sixth grade: $\beta=-.09 *$; fall term seventh grade: $\beta=-.18^{* *}$; spring term seventh grade: $\beta=-.20^{* *}$ ). In fall term of grade 7 , there was a small negative effect of maternal Math perceptions on students English academic self-concept $(\beta=-.09 *)$.

Within academic domains, grade effects were partially mediated though maternal competence perceptions (indirect effects: Math: spring term sixth grade: $\beta=.06$., $t=3.28, p<.01$; fall term seventh grade: $\beta=.06, t=2.00, p<.05$; spring term seventh grade: $\beta=.14, t=4.61, p<.01$; English: spring term sixth grade: $\beta=.07, t=3.50$, $p<.01$; fall term seventh grade: $\beta=.06, t=2.14, p<.05$; spring term seventh grade: $\beta=.05, t=3.07, p<.01)$. A significant indirect effect indicates a significant mediation (comparable to Sobel-test). Therefore, within-domain grade effects on the academic self-concepts are mediated through the maternal competence perceptions.

Between academic domains, only negative effects of the English grade on the Math self- concept were mediated through maternal English competence perception (indirect effects: spring term sixth grade: $\beta=-.03$., $t=-2.39, p<.05$; fall term seventh grade: $\beta=-.02, t=-2.13, p<.05$; spring term seventh grade: $\beta=-.07, t=-3.92, p<.01$ ). Thus, grade information regarding the children's achievement in English was perceived by the mothers and incorporated in their competence beliefs. Adolescents used information provided through their mothers' competence perception from both academic domains for their own self-concept construction in Math. Here, within and cross-domain grade effects were mediated through maternal competence perceptions. All above reported grade effects are the direct effect, which means that they are controlled for the maternal competence predictions.

The test of invariant effects over time was conducted in two steps. Firstly, six alternative models were specified. Separately for each academic domain (1) the grade effects on the students' self-concepts, (2) the grade effects on the maternal perceived competence, and (3) the effects of the maternal competence perception on the student's self-concepts were set invariant between spring term seventh grade, fall term seventh grade, and spring term seventh grade. Except for the grade effects on maternal perceptions in English, $T R d^{2}(d f=4)=5.82, p>.05$, all regression coefficients differed between time points, as indicated by a significantly worse model fits of the restricted models, $T R d \mathrm{~s}^{2}(d f=4)>9.65, p \mathrm{~s}<.05$.

Because we assume that after the transition, grades temporarily lose predictive value whereas maternal views gain predictive value for the students' self-concept of ability; in the second block, two alternative models were specified. For each academic domain separately, the differences between the grades-on-self-concept-effect and the mother-on-self-concept-effect were set equal over the measurement occasions. The fit of these models was significantly worse than the reference, $T R d s^{2}(d f=2)>231.79$, $p s<.01$, indicating a significant temporal shift in the relative effect sizes of maternal perceptions and grades on the students' academic self-concepts during school transition.

\section{Discussion}

The main goal of this study was to investigate the association of school transition with changes in self-concepts of ability in the domains of Math and English. Grades and parental competence perceptions as sources of information for this construction process were investigated before, during, and after secondary school transition. 


\section{Secondary School Transition}

The major interest of this study was on changes across the secondary school transition. Like others, we found support for the hypothesized destabilization of students' academic self-concepts associated with this school transition (Cole et al., 2001; Meckelmann, 2004; Watt, 2004). With the same dataset used in this study, Wigfield et al. (1991) showed decreases in the mean levels of the academic self-concepts during secondary school transition. A reason for this pattern (destabilization and decreases) has been suggested in changing teachers' efficacy, organization of instruction, cognitive level of the academic content, grading practices, motivational goals, as well as changes in the social comparison groups (frame of reference) available to the students after this particular school transition (for a review Eccles et al., 1998).

On the mean level, maternal competence perceptions decreased as well. But stability correlations (inter-individual stabilities) were higher than the respective adolescents' coefficients. Parents likely base their competence appraisals on a longer time frame and more observations as compared to teachers leading to this increased maternal stability during school transition. It seems plausible to assume that this stability during this time of major contextual changes qualifies the parental beliefs as a more secure source of information for students' self-evaluative constructions, as compared to the grades that are dependent on the external frame of reference.

\section{Flexibility in Self-concept Construction}

As expected, the longitudinal predictive effects of grades on the self-concepts of ability were weaker across the school transition than before and approximately six months after the transition. As long as the grading takes place in the same context, for example, the same classroom or school, a stronger association with competence beliefs was found. At the same time, as the prediction by school grades decreased, parental perceptions became stronger. These parental beliefs temporarily gained importance for the students' self-concept assessments across the transition. In the subsequent term, this effect decreased again.

It is widely agreed that there is a need for self-evaluation (Deci \& Moller, 2005; Festinger, 1954; James, 1892). The processes involved in self-evaluations are assumed to be flexible. Several motives or situational characteristics can affect the choice of the sources of information (e.g., Mussweiler, 2003; Pomerantz et al., 2001). If one regards the self-concept of ability as a flexible construction based on information from various sources (Eccles, 1984; Harter, 1998; Skaalvik \& Skaalvik, 2002), some of these sources may lose informational value if the frame of reference changes. Grades obtained in elementary school can be regarded as predictive only in the context in which they were given. It has been shown that grades are good indicators of achievement but only within classroom (Hoge \& Coladarci, 1989; Trautwein et al., 2006; Valtin et al., 2002). Therefore, the grades obtained in elementary school are not regarded as the best competence indicator by the students during school transition, as indicated by the decreases in the regression weights. To compensate for this decrease in the validity of elementary school grades, the implicit achievementrelated feedback obtained through parental competence perceptions appeared to increase in value in the construction process of the academic self-evaluations. This source of information was shown to be more stable during this time of change. Thus, it seems reasonable to assume that information inferred from the parental competence 
perception would be considered more reliable by the students and therefore emphasized.

After the transition, the effects of the grades, now obtained in the new frame of reference, regained their importance and validity for the self-evaluations of the students, as shown in the increased regression weights. At the same time, the effect of the parental perception decreased again, because there was no need to compensate for lacking grade information any more. However, the power of the maternal perceptions in predicting negative cross-domain changes persisted after the transition.

The importance of parents' perceptions of their children's abilities is also shown in the cross-domain predictions. Marsh and his colleagues stress cross-domain comparisons as key to internal frame of reference effects regarding several sources of competence-relevant information (e.g., Marsh \& Hau, 2004). Much of their work has focused on cross-domain effects of grades on domain-specific self-concepts. We found no evidence of such grade effects but did find evidence of the predicted negative cross-domain effects for maternal ratings of their children's Math and English abilities. The reason for the non-significant cross-domain grade effects may be the mediation of these effects through the maternal competence perceptions. This pattern has been shown on a German dataset as well (Gniewosz, 2010). Within domain, parents include achievement-related information into their competence perceptions. Since students include information derived from these perceptions from various domains, crossdomain grade effects on academic self-concepts can be mediated through the parents' competence beliefs. Thus, within and cross-domain effects contribute to the students constructions.

To sum up, we were able to show that across the school transition, grades obtained prior to the transition seem to have less informational value for the construction of the self-concept of ability than grades within an academic year. At the same time, parental views become stronger predictors over the transitional period. We assume that this might be a more general effect. Individuals' self-concepts of ability emerge out of a plethora of informational sources, such as grades, immediate and previous appraisals by parents and teachers, immediate comparisons with peers, and internal comparisons across subject areas. Due to developmental status or various other situational characteristics, such as school transitions, the relative importance of these sources may shift. If one informational source is perceived as less predictive or helpful for the construction of competence beliefs, others may be weighted more strongly to keep a sufficient evaluation base for this construction. The underlying process may stem from the motivation for self-concept evaluation. There are at least three basic motives linked to the self-concept construction: self-enhancement - the desire for a positive self-concept (Brown, 1991; Greenwald, 1980), self-verification - the desire for self-concept consistency and stability (Festinger, 1957; Swann, Rentfrow, \& Guinn, 2003), and selfassessment - the desire for accurate self-perceptions (Festinger, 1954; Trope \& Pomerantz, 1998). Related to the presented findings, the change in the relative importance of parental perceptions vs. grades is best interpreted within the frame of selfverification and self-assessment motives. In order to keep a stable, consistent, and accurate competence self-evaluation, the most stable and diagnostic information is selected (e.g., Atkinson, 1964; Sedikides, 1993). Our flexibility assumption is directed toward the use of informational sources. As the general level of the inter-individual stabilities indicate, self-concepts of abilities are more or less stable on that level. Flexibility, however, has been shown in the process of keeping these constructions stable, following self-verification and self-assessment motives. 


\section{Limitations}

Our results need to be interpreted with some limitations kept in mind. Firstly, we cannot rule out the possibility that the changes in the result patterns interpreted as school transition effects are driven by comparing within-school year (pre and post transition) to between-school year (spring term sixth grade vs. fall term seventh grade) effects. Between-school year data either pre or postschool transition would be needed to be sure about the school transition as the causal factor leading to this shift in the use of informational sources. But this kind of data was not available. However, even if the school transition is not the causal factor underlying the shift in the predictive values of grades and parental competence perceptions, the effect pattern and the interpretation in terms of a flexible use of information in the construction of academic self-concepts remains the same: During contextual changes (school transition or frame of reference changes due to between school year changes) one source of information becomes less predictive whereas another source is emphasized to secure a valid and stable self-evaluation. Secondly, our sample is restricted to a specific age group and a specific transition time point. Older students might not consider parent-related information a valid source due individuation processed during adolescence. Thus, further research employing different age groups/different transition time points is needed. Thirdly, the study was restricted to maternal data. Other sources of information, such as fathers, peers, and teachers on academic competence should be considered in further research. Fourthly, the data was collected in the 1980s. We do not necessarily think that the age of the dataset would affect the result patterns because the relations between the investigated constructs (academic selfconcepts, grades, parental competence beliefs) are largely the same across various studies, conducted over the last 30 years (e.g., Frome \& Eccles, 1998 vs. Gniewosz, 2010). Furthermore, the structural characteristics of the context change induced by secondary school transition did not change much as well. However, future research should replicate the presented findings.

Moreover, the conditions leading to shifts in the relative importance of the informational sources should be directly addressed. What are the needs or the situational characteristics that trigger the new exploration of sources and the differential weighting of them? More longitudinal studies focusing on school transitions are needed to get a better picture of the processes going on in this period of change.

\section{Conclusion}

Taken together, this study provides insights into processes involved in the construction of academic self-concepts. A flexible selection and processing of information has been shown due to changes in the perceived validity of sources following motives to keep a stable, consistent, and accurate academic self-concept.

\section{References}

Arbuckle, J. L. (1996). Full information estimation in the presence of incomplete data. In G. A. Marcoulides \& R. E. Schumacker (Eds.), Advanced structural equation modeling: Issues and techniques (pp. 243-277). Hillsdale, NJ: Erlbaum.

Atkinson, J. W. (1964). An introduction to motivation. Princeton, NJ: Van Nostrand. 
Berndt, T. J., \& Mekos, D. (1995). Adolescents' perceptions of the stressful and desirable aspects of the transition to junior high school. Journal of Research on Adolescence, 5, 123-142.

Bouchey, H. A., \& Harter, S. (2005). Reflected appraisals, academic self-perceptions, and math/science performance during early adolescence. Journal of Educational Psychology, 97, 673-686.

Brown, J. D. (1991). Accuracy and bias in self-knowledge. In C. R. Snyder \& D. R. Forsyth (Eds.), Handbook of social and clinical psychology: The health perspective (pp. 158-178). New York: Pergamon Press, Inc.

Cohen, J., Cohen, P., West, S., \& Aiken, L. (2003). Applied multiple regression/correlation analysis for the behavioral sciences. Mahwah, NJ: Lawrence Erlbaum Associates.

Cole, D. A., Maxwell, S. E., \& Martin, J. M. (1997). Reflected self-appraisals: Strength and structure of the relation of teacher, peer, and parent ratings to children's self-perceived competencies. Journal of Educational Psychology, 89, 55-70.

Cole, D. A., Maxwell, S. E., Martin, J. M., Peeke, L. G., Seroczynski, A. D., Tram, J. M., et al. (2001). The development of multiple domains of child and adolescent self-concept: A cohort sequential longitudinal design. Child Development, 72, 1723-1746.

Dai, D. Y. (2002). Incorporating parent perceptions: A replication and extension study of the internal-external frame of reference model of self-concept development. Journal of Adolescent Research, 17, 617-645.

Deci, E. L., \& Moller, A. C. (2005). The concept of competence: A starting place for understanding intrinsic motivation and self-determined extrinsic motivation. In A. J. Elliot \& C. S. Dweck (Eds.), Handbook of competence and motivation (pp. 579-597). New York: Guilford Publications, Inc.

Eccles (Parsons), J. (1983). Expectancies, values and academic behaviors. In J. Spence (Ed.), Achievement and achievement motivation (pp. 75-146). San Francisco, CA: W.H. Freeman and Co.

Eccles, J. S. (1984). Sex differences in achievement patterns. In T. Sonderegger (Ed.), Nebraska symposium of motivation, Vol. 32 (pp. 97-132). Lincoln, NE: University of Nebraska Press.

Eccles, J. S. (2004). Schools, academic motivation, and stage-environment fit. In R. M. Lerner \& L. Steinberg (Eds.), Handbook of adolescent psychology (pp. 125-153). Hoboken, NJ: Wiley.

Eccles, J. S., \& Midgley, C. (1989). Stage/environment fit: Developmentally appropriate classrooms for early adolescents. In R. Ames \& C. Ames (Eds.), Research on motivation in education, Vol. 3 (pp. 139-181). New York: Academic Press.

Eccles, J. S., Midgley, C., \& Adler, T. (1984). Grade-related changes in the school environment: Effects on achievement motivation. In J. G. Nicholls (Ed.), The development of achievement motivation (pp. 283-331). Greenwich, CT: JAI Press.

Eccles, J. S., Midgley, C., Buchanan, C. M., Wigfield, A., Reuman, D., \& Mac Iver, D. (1993). Developmental during adolescence: The impact of stage/environment fit. American Psychologist, 48, 90-101.

Eccles, J. S., \& Wigfield, A. (2002). Motivational beliefs, values, and goals. Annual Review of Psychology, 53, 109-132.

Eccles, J. S., Wigfield, A., Flanagan, C. A., Miller, C., Reuman, D. A., \& Yee, D. (1989). Self-concepts, domain values, and self-esteem: Relations and changes at early adolescence. Journal of Personality, 57, 283-310.

Eccles, J. S., Wigfield, A., Harold, R. D., \& Blumenfeld, P. (1993). Age and gender differences in children's self- and task perceptions during elementary school. Child Development, 64, 830-847.

Eccles, J. S., Wigfield, A., \& Schiefele, U. (1998). Motivation to succeed. In W. Damon \& N. Eisenberg (Eds.), Handbook of child psychology. 5th ed., volume 3: Social emotional and personality development (pp. 1017-1095). New York: John Wiley \& Sons.

Elliot, A. J., \& Mapes, R. R. (2005). Approach-avoidance motivation and self-concept evaluation. In A. Tesser, J. V. Wood, \& D. A. Stapel (Eds.), On building, defending and regulating the self: A psychological perspective (pp. 171-196). Hove: Psychology Press.

Festinger, L. (1954). A theory of social comparison processes. Human Relations, 7, 117-140. Festinger, L. (1957). A theory of cognitive dissonance. Evenston, IL: Row, Peterson. 


\section{Burkhard Gniewosz, Jacquelynne S. Eccles and Peter Noack}

Finger, J. A., \& Silverman, M. (1996). Changes in academic performance in the junior high. Personnel and Guidance Journal, 45, 157-164.

Fredricks, J. A., \& Eccles, J. S. (2002). Children's competence and value beliefs from childhood through adolescence. Developmental Psychology, 38, 519-533.

Frome, P. M., \& Eccles, J. S. (1998). Parents' influence on children's achievement-related perceptions. Journal of Personality and Social Psychology, 74, 435-452.

Gniewosz, B. (2010). Die konstruktion des akademischen selbstkonzeptes: Eltern und zensuren als informationsquellen [The construction of the academic self-concept: Parents and grades as sources of information]. Zeitschrift für Entwicklungs- und Pädagogische Psychologie, 42, 133-142.

Greenwald, A. G. (1980). The totalitarian ego: Fabrication and revision of personal history. American Psychologist, 35, 603-618.

Harter, S. (1998). The development of self-representations. In W. Damon \& N. Eisenberg (Eds.), Handbook of child psychology, 5th ed.: Vol 3. Social, emotional, and personality development (pp. 553-617). New York: John Wiley \& Sons, Inc.

Harter, S., Whitesell, N. R., \& Kowalski, P. S. (1992). Individual differences in the effects of educational transitions on young adolescents' perceptions of competence and motivational orientation. American Educational Research Journal, 29, 777-807.

Hoge, R. D., \& Coladarci, T. (1989). Teacher-based judgments of academic achievement: A review of literature. Review of Educational Research, 59, 297-313.

Hoge, R. D., Smit, E. K., \& Hanson, S. L. (1990). School experiences predicting changes in self-esteem of sixth- and seventh-grade students. Journal of Educational Psychology, 82, $117-127$.

Jacobs, J. E., Davis-Kean, P., Bleeker, M., Eccles, J. S., \& Malanchuk, O. (2005). 'I can, but I don't want to': The impact of parents, interests, and activities on gender differences in math. In A. M. Gallagher \& J. C. Kaufman (Eds.), Gender differences in mathematics: An integrative psychological approach (pp. 246-263). Cambridge: Cambridge University Press.

Jacobs, J. E., \& Eccles, J. S. (1992). The impact of mothers' gender-role stereotypic beliefs on mothers' and children's ability perceptions. Journal of Personality and Social Psychology, 63, 932-944.

Jacobs, J. E., \& Eccles, J. S. (2000). Parents, task values, and real-life achievement-related choices. In C. Sansone \& J. M. Harackiewicz (Eds.), Intrinsic and extrinsic motivation: The search for optimal motivation and performance (pp. 405-439). San Diego, CA: Academic Press, Inc.

James, W. (1892). Psychology. New York: Henry Holt and Company.

Kline, R. B. (1998). Principles and practice of structural equation modeling. New York: Guilford Press.

Little, R. (1988). A test of missing completely at random for multivariate data with missing values. Journal of the American Statistical Association, 83, 1198-1202.

Marsh, H. W. (1986). Verbal and math self-concepts: An internal/external frame of reference model. American Educational Research Journal, 23, 129-149.

Marsh, H. W. (1990). The structure of academic self-concept: The Marsh/Shavelson model. Journal of Educational Psychology, 82, 623-636.

Marsh, H. W., Byrne, B. M., \& Craven, R. (1992). Overcoming Problems in Confirmatory Factor Analyses of MTMM Data: The Correlated Uniqueness Model and Factorial Invariance. Multivariate Behavioral Research, 27, 489-507.

Marsh, H. W., \& Hau, K.-T. (2004). Explaining paradoxical relations between academic self-concepts and achievements: Cross-cultural generalizability of the internal/external frame of reference predictions across 26 countries. Journal of Educational Psychology, 96, $56-67$.

Marsh, H. W., Köller, O., Trautwein, U., Lüdtke, O., \& Baumert, J. (2005). Academic selfconcept, interest, grades, and standardized test scores: Reciprocal effects models of causal ordering. Child Development, 76, 397-416.

McDougall, P., \& Hymel, S. (1998). Moving into middle school: Individual differences in the transition experience. Canadian Journal of Behavioural Science, 30, 108-120.

Meckelmann, V. (2004). Schulwechsel als kritisches lebensereignis und die entwicklung des selbstkonzeptes bei jugendlichen [School transition as critical life event and adolescent self-concept development]. Psychologie in Erziehung und Unterricht, 51, 273-284. 
Midgley, C., Feldlaufer, H., \& Eccles, J. S. (1988). The transition to junior high school: Beliefs of pre- and posttransition teachers. Journal of Youth and Adolescence, 17, 543-562.

Midgley, C., Feldlaufer, H., \& Eccles, J. S. (1989). Student/teacher relations and attitudes toward mathematics before and after the transition to junior high school. Child Development, 60, 981-992.

Mussweiler, T. (2003). Comparison processes in social judgment: Mechanisms and consequences. Psychological Review, 110, 472-489.

Muthén, B., \& Muthén, L. (2006). Mplus (version 4.2). Los Angeles, CA: Muthén \& Muthén.

Nicholls, J. G. (1979). Development of perception of own attainment and causal attributions for success and failure in reading. Journal of Educational Psychology, 71, 94-99.

Pomerantz, E. M., Saxon, J. L., \& Kenney, G. A. (2001). Self-evaluation: The development of sex differences. In G. B. Moskowitz (Ed.), Cognitive social psychology (pp. 59-75). Mahwah, NJ: Lawrence Erlbaum Associates.

Raudenbush, S. W., \& Bryk, A. S. (2002). Hierarchical linear models: Applications and data analysis methods, 2nd ed. London: Sage Publications.

Rosenholtz, S. J., \& Simpson, C. (1984). The formation of ability conceptions: Developmental trend or social construction? Review of Educational Research, 54, 31-63.

Ruble, D. N. (1994). A phase model of transitions: Cognitive and motivational consequences. In M. P. Zanna (Ed.), Advances in experimental social psychology, Vol. 26 (pp. 163-214). New York: Academic Press.

Ruble, D. N., \& Seidman, E. (1996). Social transitions: Windows into social psychological processes. In E. T. Higgins \& A. W. Kruglanski (Eds.), Social psychology: Handbook of basic principles (pp. S. 830-S. 856). New York: Guilford Press.

Satorra, A., \& Bentler, P. M. (1999). A scaled difference chi-square test statistic for moment structure analysis. Psychometrika, 66, 507-514.

Schafer, J. L., \& Graham, J. W. (2002). Missing data: Our view of the state of the art. Psychological Methods, 7, 147-177.

Sedikides, C. (1993). Assessment, enhancement, and verification determinants of the selfevaluation process. Journal of Personality and Social Psychology, 65, 317-338.

Seidman, E., Allen, L., Aber, J. L., \& Mitchell, C. (1994). The impact of school transitions in early adolescence on the self-system and perceived social context of poor urban youth. Child Development, 65, 507-522.

Skaalvik, E. M., \& Rankin, R. J. (1995). A test of the internal/external frame of reference model at different levels of math and verbal self-perception. American Educational Research Journal, 32, 161-184.

Skaalvik, E. M., \& Skaalvik, S. (2002). Internal and external frames of reference for academic self-concept. Educational Psychologist, 37, 233-244.

Spinath, B., \& Spinath, F. M. (2005). Development of self-perceived ability in elementary school: The role of parents' perceptions, teacher evaluations, and intelligence. Cognitive Development, 20, 190-204.

Swann, W. B., Jr, Rentfrow, P. J., \& Guinn, J. S. (2003). Self-verification: The search for coherence. In M. R. Leary \& J. Tangney (Eds.), Handbook of self and identity (pp. 367-366). New York: Guilford Press.

Trautwein, U., Lüdtke, O., Marsh, H. W., Köller, O., \& Baumert, J. (2006). Tracking, grading, and student motivation: Using group composition and status to predict self-concept and interest in ninth-grade mathematics. Journal of Educational Psychology, 98, 788-806.

Trope, Y., \& Pomerantz, E. M. (1998). Resolving conflicts among self-evaluative motives: Positive experiences as a resource for overcoming defensiveness. Motivation \& Emotion, 22, $53-72$.

Valtin, R., Schmude, C., Rosenfeld, H., Darge, K., Ostrop, G., Thiel, O., et al. (2002). Was ist ein gutes zeugnis? Noten und verbale beurteilungen auf dem prüfstand [What is a good report card? Grades and verbal feedback put to test]. Weinhem: Juventa.

Watt, H. M. G. (2004). Development of adolescents' self-perceptions, values, and task perceptions according to gender and domain in 7th- through 11th-grade Australian students. Child Development, 75, 1556-1574.

Wigfield, A., Byrnes, J. P., \& Eccles, J. S. (2006). Development during early and middle adolescence. In P. A. Alexander \& P. H. Winne (Eds.), The handbook of educational psycho$\operatorname{logy}$ (pp. 87-113). Mahwah, NJ: Lawrence Erlbaum Associates. 


\section{Burkhard Gniewosz, Jacquelynne S. Eccles and Peter Noack}

Wigfield, A., Eccles, J. S., Mac Iver, D., Reuman, D. A., \& Midgley, C. (1991). Transitions during early adolescence: Changes in children's domain-specific self-perceptions and general self-esteem across the transition to junior high school. Developmental Psychology, 27, 552565 .

Wigfield, A., \& Wagner, A. L. (2005). Competence, motivation, and identity developments during adolescence. In A. J. Elliot \& C. S. Dweck (Eds.), Handbook of competence and motivation (pp. 222-239). New York: Guilford Press.

\section{Acknowledgements}

This research was made possible by grants to Jacquelynne S. Eccles from the National Institute of Mental Health (MH31724), the National Institute of Child Health and Human Development (HD17296), the National Science Foundation (BNS-8510504), and a grant to Peter Noack from the German Research Foundation (NO 213/7-1). The authors would like to thank the following people for their role in the design and collection of these data: Carol Midgley, Allan Wigfield, Harriet Feldlaufer, Douglas McIver, David Reuman, Janis Jacobs, Bonnie Barber. Moreover, the authors want to thank Juliane Strecker, Stefan Haubold, Sarah Thomann, and Susanne Sassenberg.

\section{Notes}

1. We deliberately deviated from cross-lagged modeling, because we think that the students employ the most recent information for their self-concept constructions. The most recent grades are those obtained the preceding term whereas the most recent maternal appraisals are the contemporaneous ones. Since we controlled for the auto-regressions in the dependent variables, the interpretations of the results go beyond cross-sectional models because changes in the dependent measures are explained.

2. TRd is the test statistic of the scaled $\chi^{2}$-difference test. 


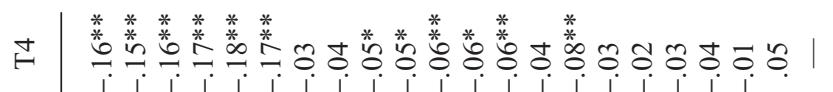

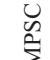

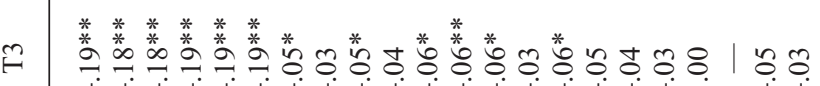
$i_{i} i_{i} i_{i} i_{i} i_{i} i_{i} i_{i} i_{i} i_{i} i_{i} i_{i} i_{i}$

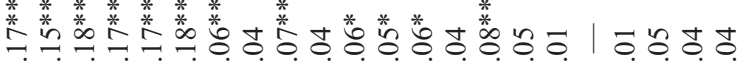

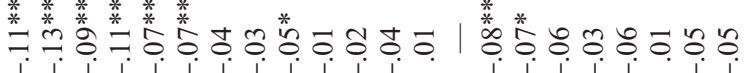

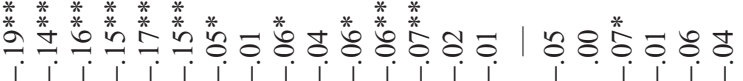

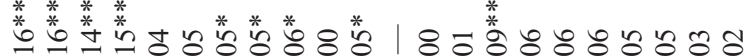

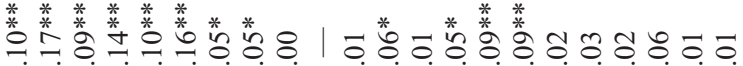

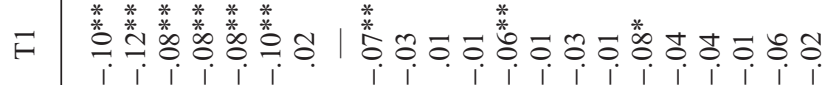

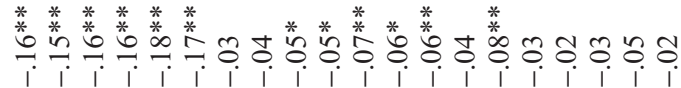

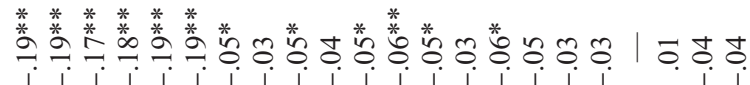

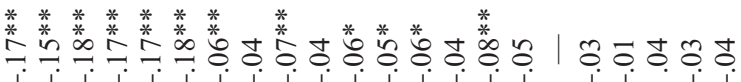

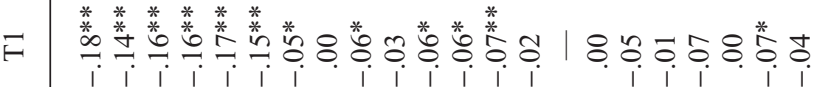

土 $\stackrel{*}{*} \stackrel{*}{*} \stackrel{*}{*} \frac{*}{*}=$ m t

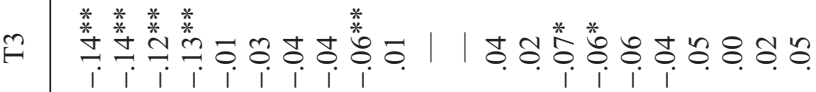

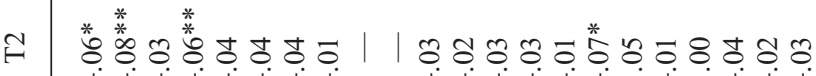

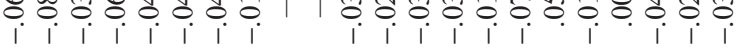

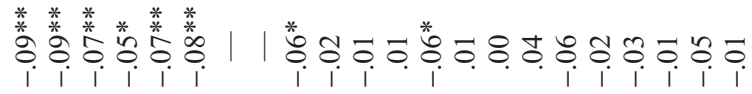

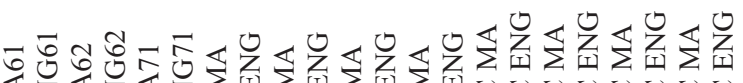

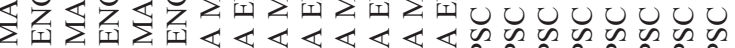

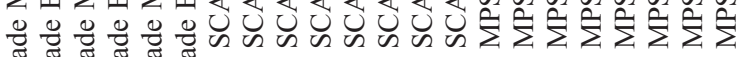
שี 


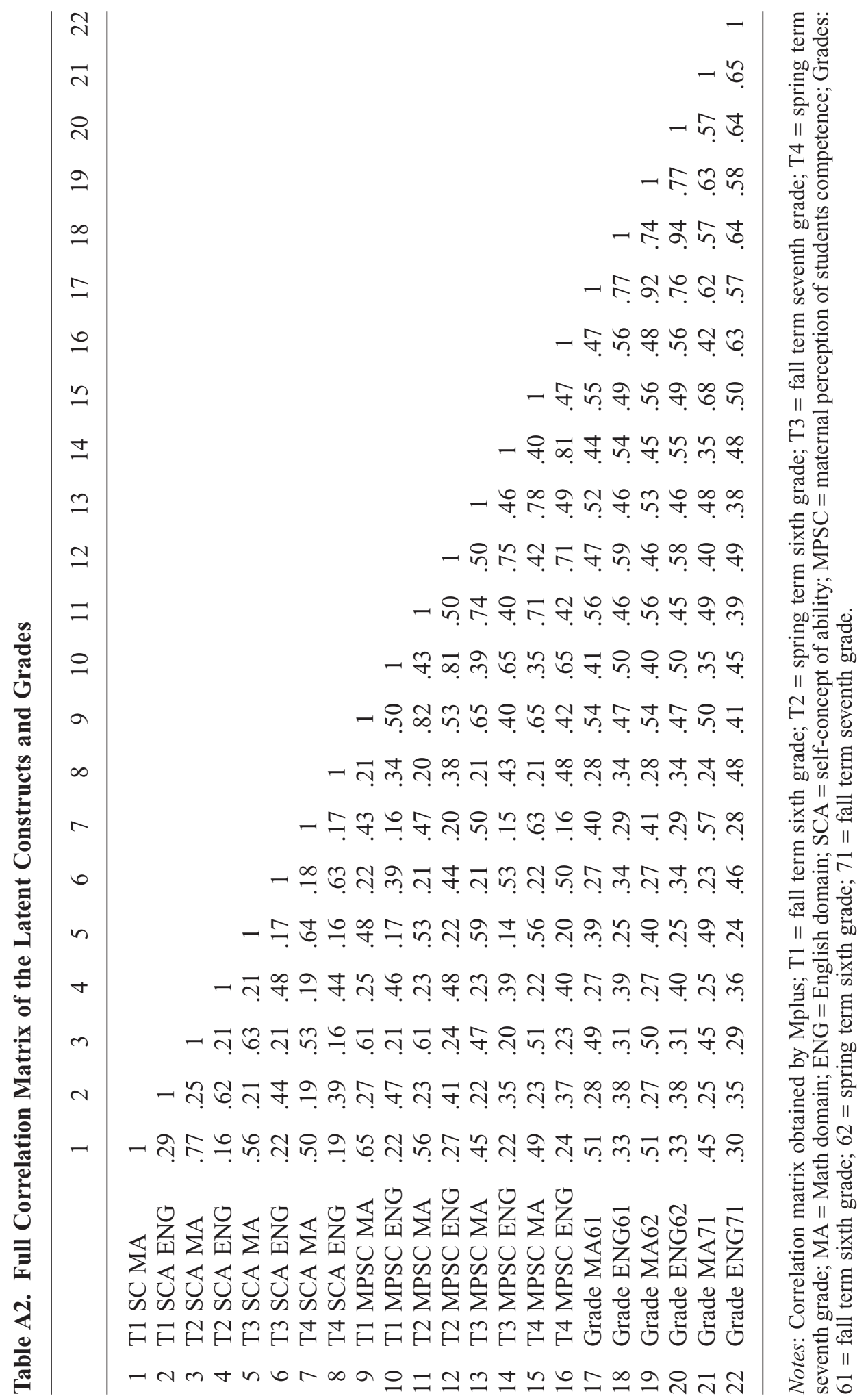


Table A3. Within- and Cross-domain Autoregressive Paths

\begin{tabular}{|c|c|c|c|c|c|c|}
\hline & \multicolumn{2}{|c|}{$\mathrm{T} 1 \rightarrow \mathrm{T} 2$} & \multicolumn{2}{|c|}{$\mathrm{T} 2 \rightarrow \mathrm{T} 3$} & \multicolumn{2}{|c|}{$\mathrm{T} 3 \rightarrow \mathrm{T} 4$} \\
\hline & $\beta$ & $S E$ & $\beta$ & $S E$ & $\beta$ & $S E$ \\
\hline SCA: MA $\rightarrow$ MA & $.58 * *$ & .04 & $.37 * *$ & .04 & $.31 * *$ & .05 \\
\hline SCA: MA $\rightarrow$ ENG & $-.07 *$ & .04 & .05 & .04 & .06 & .05 \\
\hline SCA: $\mathrm{ENG} \rightarrow \mathrm{ENG}$ & $.51 * *$ & .04 & $.24 * *$ & .05 & $.44 * *$ & .04 \\
\hline SCA: ENG $\rightarrow$ MA & .04 & .03 & $.09 *$ & .03 & $.11 * *$ & .03 \\
\hline MPSC: MA $\rightarrow$ MA & $.73 * *$ & .05 & $.56^{* *}$ & .08 & $.50 * *$ & .06 \\
\hline MPSC: $\mathrm{MA} \rightarrow \mathrm{ENG}$ & $.12 * *$ & .04 & .06 & .07 & $.11^{*}$ & .05 \\
\hline MPSC: $\mathrm{ENG} \rightarrow \mathrm{ENG}$ & $.64 * *$ & .04 & $.58 * *$ & .07 & $.58 * *$ & .05 \\
\hline MPSC: $\mathrm{ENG} \rightarrow \mathrm{MA}$ & .00 & .03 & $.20 * *$ & .07 & .02 & .04 \\
\hline
\end{tabular}

Note $: \mathrm{T} 1=$ fall term sixth grade; $\mathrm{T} 2=$ spring term sixth grade; $\mathrm{T} 3=$ fall term seventh grade; $\mathrm{T} 4$ $=$ spring term seventh grade; $\mathrm{MA}=$ Math domain; $\mathrm{ENG}=$ English domain; $\mathrm{SCA}=$ self-concept of ability; MPSC = maternal perception of students competence. Coefficients are standardized regression coefficients obtained by M-Plus.

$* p<.05, * * p<.01$. 